author concludes that a certain amount of podzolization did, in fact, take place under forest, but much of the degradation is secondary. Of the possible degrading agents involved, climate is clearly important, as is vegetation cover, but rather conflicting evidence suggests that neither of these is of overriding importance, and the greatest influence seems to have been the nature of the parent material. A very interesting section is that in which the transition from forest to heath is related to various agencies and especially to the part played by Neolithic Man, though it is stressed that the use of fire by Mesolithic and possibly also by Palæolithic Man may have had a greater effect than is often realized. Some comments on the regeneration of degraded soils show that this relatively uncommon phenomenon is usually associated with a grass cover and, therefore, with agriculture, but the depth to which such regeneration occurs suggests that trees may also play an important part. Rather curiously, there is no mention of the extensive work by Ovington on the circulation of nutrients in conifer plantations, especially on the heaths of the Breck.

The author is clearly concerned that the policy of planting conifers on already degraded heath soils can result only in further degradation, though he stops short of stating what positive steps could be taken to overcome this. It is implicit in his general conclusions that some soils could become so exhausted that they would cease to support a continuous vegetation cover at all.

It seems a pity that a Memoir of this type could not be bound in a hard cover; but there can be no excuse for neither the title nor the author's name appearing on the spine. While the printing of the text is fully up to the standard expected of the Oxford University Press, the same cannot be said for the coloured plates. I sympathize with the author's contention that soil profiles are best illustrated by colour photographs, but the reproductions provided give only the most general impression of the various horizons.

R. B. Ivimey-Cook

\section{VEGETATION AND HYDROLOGY}

\section{Vegetation and Hydrology}

By Dr. H. L. Penmen. (Technical Communication No. 53 of the Commonwealth Bureau of Soils, Harpenden). Pp. v+124. (Farnham Royal: Commonwealth Agricultural Bureaux, 1963.) 20s.

T

HE scientific problems underlying water conservation have been bedevilled by the diversity of interests and opinions pertaining to the hydrology of a land surface. The available evidence is often derived from technical investigations by agriculturists, foresters or waterengineers, working from basically different assumptions, while the approximate nature of the field techniques used has contributed greatly to the confusion. Hence this publication may be welcome, not only because it gives a survey of the pertinent literature, but also because it attempts to establish modes of approach to the underlying problems and to define them in general and scientific terms.

If climate, and especially rainfall, is determined by the movement of air masses, the only site factor that may control evaporation in the water-cycle is the vegetation cover. Assessments of the relative importance of this factor illustrate extremely well the insecurity of the premises on which alternative views depend and, in particular, the extreme differences in outlook which result from under-estimates of the importance of turbulence and of 'edge' effects in evaporation; the contrast, in short, between estimates based on small sample plots or potted plants, and those derived from a complete and extensive vegetation cover. The survey of the evidence suggests that decisive experiments in this field have not yet been achioved, so that the working hypothesis used in the final chapter may still be the safest approach. It is in essence Rakhmanov's conclusion for catchment area investigations that forest cover does not accelerate evaporation, which depends, therefore, mainly on weather. Dr. Penman leaves the data to speak for themselves. He has, however, indicated the arguments which must be applied to the meteorological approach, has dealt with the difficulties of accurate rain-gauging, the effects of vegetation in intercepting rain, and in increasing the infiltration of water while lessening run-off and soil erosion. He has given also a good discussion of the main problems involved in estimating potential evaporation. This is, therofore, much more than a technical summary, and is a work which will appeal to those with wider interests.

W. H. Pearsall

\section{COMMONWEALTH UNIVERSITIES YEARBOOK}

Commonwealth Universities Yearbook 1963

A Directory to the Universitios of the British Commonwoalth and the Handbook of their Association. Edited by J. F. Foster and T. Craig. Pp. xxxii + 1826. (London: Association of Universities of the British Commonwealth, 1963.) 105s.; 15 dollars.

" GDUCATION may be said to be permanently in a state of transition and this is to the good. Without change there is no development; without change there is only decay." Thus wrote the reviewer of the second edition (1915) of what was then called The Yearbook of the Universities of the Empire, a directory compiled and published by the University Bureau of the British Empire (Nature, 96,$317 ; 1915)$. In the years that have followed there have been such great developments that the Yearbook, which was then 717 pages, dealt with 54 universities and affiliated colleges, and cost $7 s .6 d$., now, in its fortieth edition, extends to 1,826 pages, deals with 150 universities and affiliated colleges and costs 105s. Moreover the Bureau, founded in 1913, has very recently become the Association of Commonwealth Universities and the directory The Commonwealth Universities Yearbook. The fortieth edition thus appears in the Jubilee year of the founding body.

The Yearbook is published as a directory to university institutions in all countries of the Commonwealth and is not restricted to membership of the Association. Essentially it is divided up into 18 sections dealing with the countries of the Commonwealth. Each of the sections has a "national introduction", primarily intended as a functional guide for people who wish to attain a general background on university education in that particular country. Then follow the separate university entries and, department by department, their academic staff. A.t the end of each university section are given details of administrative and other staff, affiliated colleges and halls of residence and general information. In so doing the Yearbook fulfils tho function of providing basic data to assist a student proposing to go to a Commonwealth country. In addition to the particulars, for example, of "first degrees" and "higher degrees", there is a detailed chart of "Subjects of Study".

In all there are seven appendixes. Appendixes 1 and 2 contain full details of the universities of the Republic of Ireland and the Republic of South Africa. Appendix 3 is a summary of the admission requirements of universities in Australia, Canada and the United Kingdom. Appendix 4 deals with information pertaining to students from other countries in United Kingdom universities. Appendix 5 deals with British academic institutions outside the Commonwealth, and Appendix 6 gives a short bibliography. Details of the Commonwealth scholarship and fellowship plan are dealt with in Appendix 7, and finally, Appendix 8 gives a full account of the Association of Universities of the British Commonwealth. There are excellent general and name indexes. 